\title{
Erratum to: A Rare Type of Double Aortic Arch Diagnosed by Echocardiography in an Asymptomatic 9-Year-Old Patient
}

\author{
Christina Trapali • Angeliki Nika • \\ Maria Papaphylactou • Nicoletta Iacovidou
}

Published online: 9 April 2010

(C) Springer Science+Business Media, LLC 2010

Erratum to: Pediatr Cardiol

DOI 10.1007/s00246-010-9681-1

Unfortunately the name of the third author was inadvertently misspelled in the original version. The name of the author should be Maria Papaphylactou.

The online version of the original article can be found under doi:10.1007/s00246-010-9681-1.

C. Trapali · M. Papaphylactou

Department of Cardiology, University of Athens,

"P \& A Kyriakou" Children's Hospital, Athens, Greece

A. Nika $\cdot$ N. Iacovidou

2nd Department of Paediatrics, University of Athens,

"P \& A Kyriakou" Children's Hospital, Athens, Greece

N. Iacovidou $(\bowtie)$

3, P. Mela Street, 16233 Athens, Greece

e-mail: niciac@otenet.gr 